\title{
Developing a smart port architecture and essential elements in the era of Industry 4.0
}

\author{
Hokey Min ${ }^{1}$
}

Accepted: 22 December 2021 / Published online: 23 February 2022

(c) The Author(s), under exclusive licence to Springer Nature Limited 2022

\begin{abstract}
With rapid technological innovations spurred by the Fourth Industrial Revolution (Industry 4.0), today's seaports are pressured to transform the way they operate in order to handle traffic flows. Such a transformation calls for the development of a smart port system. Despite the growing interest in smart ports, their underlying framework, architecture, and potential ramifications for port productivity are not well documented in the maritime logistics literature. To help port communities better comprehend smart port concepts and successfully develop a smart port within a global supply chain, this paper synthesizes core smart port concepts, designs underlying architecture, and proposes specific milestones for monitoring the smart port development project. We use content analysis and then we identify key success factors (e.g., essential components for the smart port architecture, value propositions, smart port performance metrics) for the establishment and sustainable growth of the smart port. The paper also aims to provide practical guidance for dealing with smart port challenges and opportunities. Our research reveals that a smart port reduces port-user response time, improves port asset utilization, and enhances maritime logistics visibility by automating and integrating end-to-end port operations digitally without human intervention.
\end{abstract}

Keywords Smart port - Technological innovation · Intelligent systems · Artificial intelligence $\cdot$ Global maritime logistics $\cdot$ Change management

Hokey Min

hmin@bgsu.edu

1 Good Chair in Global Supply Chain Strategy, Department of Management, Allen and Carol Schmidthorst College of Business, Bowling Green State University, Maurer Center 312 , Bowling Green, $\mathrm{OH}$, USA 


\section{Introduction}

The ongoing COVID-19 pandemic has affected every facet of today's business community in such a way that it forces every organization to divest itself of legacy thinking and to embrace a new way of thinking and doing things. The new way includes technological innovation built upon digital transformation that can drive massive productivity gains and subsequent business success through easier access to the wealth of real-time information. This digital transformation entails digitization (computerization) of physical resources and their integration with the worldwide Internet network. In addition, it requires cultural and business paradigm shifts in how a company operates and delivers value to its customers through the rapid adoption of (computerized) technology (Crittenden et al. 2019). Such technology is represented by the following features (Ślusarczyk 2018; Oztemel and Gursev 2020):

(1) Internet of Things (IoT) A connection of physical devices to the Internet that allows different devices to "talk" to (communicate with) each other over the Internet. Especially, the industrial Internet of Things (IIoT) that are built upon real-time operating systems, graphical user interfaces, and advanced networking, and security platforms enable the accumulation of big data advance and thus become essential for artificial intelligence (AI) development (Sisinni et al. 2018).

(2) Man and machine interface A conversion of human-intelligible commands into machine commands and a reverse conversation of machine feedback into human understandable information. This interface helps AI to replicate and imitate the thought process of humans. Thus, this interface is essential for hyper-automation that enables the port authority to automate everything that can be automated throughout the end-to-end port operations.

(3) Cyber physical system (CPS) A creation of "smart" objects that allow for autonomous decision-making capability based on real-time information gathered from the IoT. CPS minimizes human involvement by creating a system that seamlessly integrates computational algorithms with physical components and multiple mobile networks.

Generally, a cyber-physical system (CPS) aims to integrate sensor technology, data computation, and information networking into physical objects and infrastructure by connecting them to the Internet of Things (IoT) (NSF 2018). The emergence of the CPS is supported by sensor technology, which converts a physical phenomenon into an electronic signal and mimics human sensing capabilities (e.g., musical-rhythmic, visual-spatial, verbal-linguistic, logical-mathematical, and bodily-kinaesthetic sensing) (Wilson 2005). As such, sensor technology has blurred the boundary between man and machine and has begun to replace a human role in managing business activities. As a machine takes over human activities, the machine not only provides humans with more time and freedom but also reduces human error and response time to rapid changes in today's dynamic business environments. In addition, the CPS fueled by IoT can enhance the machine-to-machine (M2M) connectivity that, in turn, increases the opportunity for faster and more accurate 
communication. Since the improved connectivity among multiple ports, carriers, and shippers enables them to communicate and interact with each other more frequently, the CPS can be a catalyst for establishing collaborative commerce that creates synergistic effects via electronically linked port activities and related business transactions. Considering the aforementioned benefit potentials, it is worth assessing the true value of CPS and exploring the possibility of CPS applications to port environments. Despite its positive value, CPS applications to a seaport setting are still rare due in part to challenges associated with the maritime logistics interoperability, scalability, and security, while it has been utilized more frequently in education, security, health care, and transportation sectors (Chen 2017).

One of the visions of CPS is to develop a smart port where port communities including carriers and shippers are working together with collaborative robots through man-technology interactions. A smart port is generally referred to as an intelligent digital port that can operate autonomously via the self-configured, selfprotective, more adaptive, more secure, more responsive, and highly connected port system. The smart port is typically designed to improve its operational and environmental efficiencies through harmonious communication among all the devices, vessels, terminals, and equipment on the shipyards (Jun et al. 2018; Karaś 2020; Molavi et al. 2020a, b; Maglić et al. 2021). In a smart port, maritime logistics operations are digitally integrated and monitored based on the real-time information available on a range of devices including smartphones and tablets. In a nutshell, a smart port is intended to create flexible, reconfigurable, agile, and environmentally friendly port systems. Nuances of a smart port contain the efficient use of port resources with no waste, the maximization of port values, port technology innovation, intelligent port problem solving via AI, smart logistics operations in the hinterland, and reduction in energy consumption and pollutant emissions in port operations. Thanks to the enormous benefit potentials of a smart port, the global smart port market is expected to reach $\$ 13.9$ billion by 2027 at a cumulated average growth rate (CAGR) of $32.4 \%$ (Grandview Research 2020). Ports of Rotterdam, Hamburg, and Quebec that took pioneering smart port initiatives are examples reflecting such a trend.

As shown in Fig. 1, key components of the smart port include (1) smart infrastructure; (2) smart traffic flows; and (3) smart logistics. The smart infrastructure aims to increase productivity and utilization of digital technology, essential for
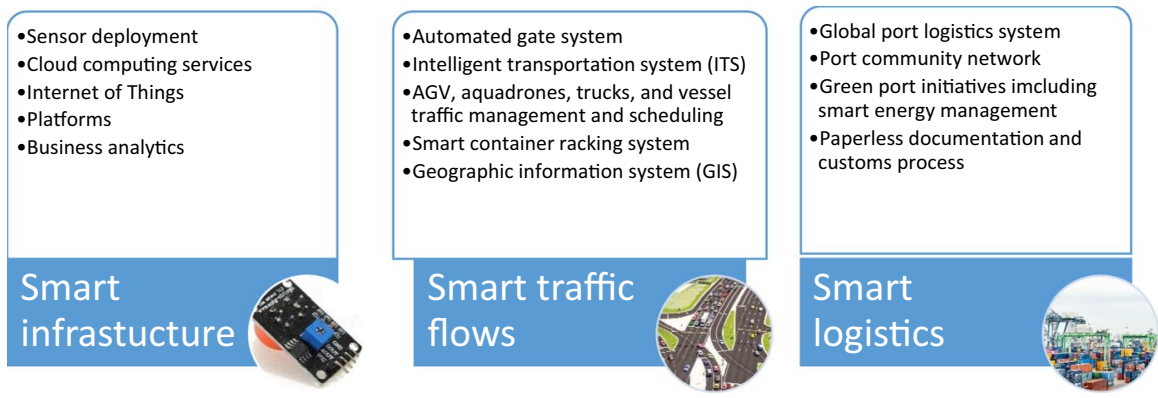

Fig. 1 Key components of a smart port 
automatic port operations. Smart traffic flows assure the seamless and efficient flows of moving assets, such as automated guided vehicles (AGVs), trucks (including driverless trucks), and remotely controlled aquadrones across the port and hinterland areas. To elaborate, autonomous vehicles such as AGVs, driverless trucks, and aquadrones, assisted by sensors, video cameras, a geographic information system (GIS), and an intelligent transportation system (ITS), would allow for uninterrupted traffic flows at the port even in the cases of labor strike incidents, labor shortages, and vehicle operator absenteeism. Despite uncontrollable dangers and high costs associated with self-driving mechanisms, autonomous vehicles will be suitable for smart port operation because a port typically has closed and highly structured environments where vehicle routes and driving tasks are standardized and roads tend to be flat and straight. Thus, autonomous vehicle maneuvering and control at the port pose few dangers and risks. Especially, autonomous vehicle operations complemented by ITS can not only smooth out port traffic flows but also improve traffic safety due to the ITS's capability to avoid traffic congestion and vehicle collision. Furthermore, aquadrones can be used to pick up floating debris and garbage on the water and thus help reduce port pollution without harming fish and birds.

Smart logistics primarily supports the automatic movement and handling of containers through unmanned (autonomous) cranes and equipment while facilitating communications among port stakeholders. In addition, it includes the efforts to sustain the port environment protection.

More specifically, smart infrastructure consists of five key elements: (1) sensor deployment, (2) cloud computing services, (3) Internet of Things (IoT), (4) platforms, and (5) business analytics. To elaborate, sensors are capable of measuring pressure, temperature, humidity, gas flows, magnetic fields, radiation, and ultrasounds, while allowing the computation of the mean, standard deviation, and variance for a set of measurements (Kersey 1996; Wilson 2005). As such, they can help detect any abnormality and damage to the port infrastructure and process. Data obtained from sensors allow for faster reaction to any problems and subsequently help eliminate any potential problems before they get worse.

Cloud computing services provide on-demand computing resources such as data, software, platform, and infrastructure via hosted services on the Internet and thus enhance computing power while saving costs. In other words, cloud computing services provide scalable, personalized, updated, and inexpensive IT infrastructure on-demand, which can be accessed in a simple, pervasive way via remote "cloud" computing resources (Wang et al. 2010). Thus, those services would make the information and communication technology (ICT) needed for smart ports more accessible and scalable. IoT is designed to link a network of vessels, port operators, and physical objects (including cranes and wearable devices) to the ubiquitous Internet (Xia et al. 2012; SAS 2018; Faulds and Raju 2019). Through enhanced ship traceability and ubiquitous connectivity, IoT aims to facilitate data gathering/sharing, machine-to-machine communications, interaction, and channel integration across the entire supply chain (Caro and Sadr 2019). As such, IoT can ramp up the flow of real-time streaming data in a port setting and subsequently improve smart port operations by increasing the opportunity to respond to changing port environments promptly and then take quick corrective actions, if necessary. 
In particular, to transform real-time data from different sources (e.g., sensors on ships, cranes, and yards) into meaningful information, a smart port necessitates a digital platform that consists of the right software and hardware devices. This platform should help plan, deliver, and execute mobility solutions based on the information created by IoT while helping to connect and then automate port equipment. In addition, it helps identify which freight each ship is carrying, track arriving ships in real-time, and keep track of cargo. In general, an IoT platform is a multi-layer technology that facilitates the integration of any (remotely) connected devices and data collection from these devices. The main role of this platform is to help port authorities derive insights or business intelligence from the collected data through data visualization and subsequently speed up the port authority's responses to end-to-end maritime logistics activities (KaaIoT Technologies 2019; Kahn 2019). In a nutshell, the IoT platform helps facilitate device management, handle hardware/software communication protocols, collect/analyze data, facilitate data flow, and enhance the functionality of smart applications (DA-14 Corp 2018). Examples of such a platform include PTC's ThingWorx, GE Predix, ABB Ability, Siemens MindSphere, and SAP-ERP (Nilsson 2018). These platforms can be categorized into four different types: (1) end-to-end IoT platform that provides the hardware, software, connectivity, security, and device management tools to handle a large number of concurrent device connections; (2) connectivity management platform that offers low power and low-cost connectivity management solutions through Wi-Fi and cellular technology; (3) IoT cloud platform that reduces the complexity of building your complex network stack and offer the backend services to monitor and track a large number of simultaneous device connections; (4) data platform that combines many of the tools for routing device data and visualizing data analytics (Lee 2018). Regardless of its type, the most desirable form of the platform should be able to self-configure, selfadjust, and self-optimize port operations in the cases of supply chain disruptions and port-demand variations.

\section{Prior literature}

Research on a smart port is at the nascent stage due to the newness of its concept and thus little is documented about that concept and development plans. As such, prior research on smart port developments is scant (Bessid et al. 2020; Yau et al. 2020). Nevertheless, some pioneering studies on the smart port have been conducted in the recent past. One of those studies includes Heilig et al. (2017a) who explained what inspired smart port development. They recognized that digitalization was one of the biggest motivating factors for smart port development. They also presented a conceptual game-theoretic framework that allowed benefits and cost allocations of port resources to smart port development from various organizational perspectives. A key contribution of their proposed framework was the establishment of a connection between the cooperative game theory model and collaborative port development strategies. Similarly, Heilig et al. (2017b) classified the evolution of digital transformation into three levels (generations) and explained how such evolution impacted smart port development. They noted that modern information technology 
and system (IT/IS) was a key enabler for smart port development. In addition, they argued that the formation of an inter-organizational network was essential for the smart port's success. Yang et al. (2018) believed that the Internet of Things (IoT), comprising sensors, actuators, and embedded systems, should make up the key infrastructure of a smart port, and then they compared the traditional port with the smart port in terms of operational and economic efficiencies. They noted that the smart port would incur higher construction/maintenance costs than the traditional port but could save port labor and transportation costs more than the traditional port, whereas it created less pollution than the traditional port. Chen et al. (2019) stressed the importance of port intelligent technology and sustainable green port handling to smart port development. The authors argued that concepts of a green port and a smart port were not independent of each other. They proposed an interpretive structural model to examine the critical factors and governance framework for the smart port development. Some of those key critical factors were cooperation between ports and shippers, intelligent technology innovation ("intelligentization"), and port environment protection.

More recently, Karaś (2020) summarized the smart port concept and described how the port evolved from the traditional port to the smart port of today. He conducted the case study of Port of Rotterdam, Port of Gdynia, Port of Antwerp, and Port of Gothenburg to illustrate how the smart port concept was implemented in those ports. Molavi et al. (2020a) conducted a case study of 14 ports to assess their smart port performance using the smart port index (SPI) that they developed. One of the important findings of their study was the fact that the smartness of a port related more to ideology than technology and physical infrastructure. They also observed that region-specific variables (e.g., a port located in a low-income area; R\&D expenditure; and energy intensity of the economy) and government policies (e.g., inconsistent port governance frameworks; the transfer of assets from public entities to private sectors) affected port performance. As such, smart ports located in wealthier countries, open to innovation and committed to environment-friendliness, tended to perform better. Similarly, González et al. (2020) developed smart port indicators that were designed to measure and then rank ten smart ports in Spain. They used the Delphi method to select indicators, and then measure smart port performance. Their Delphi panel indicated that the digitalization of port security, customs processes, and interaction with clients were important indicators that could dictate port performance. Automation of port processes was found to be another important indicator. On the other hand, the economic indicators (e.g., mooring/docking utilization rate) and environmental indicators (e.g. water quality, sustainable waste management) were relatively insignificant. Molavi et al. (2020b) illustrated how a set of smart port index metrics could be incorporated into the port microgrid (a localized energy network that intends to provide backup power to port facilities using renewable energy) planning process using numerical examples. For such demonstration, they developed a two-stage stochastic mixed-integer programming model. The model demonstrated the way a set of SPI metrics could improve the smartness of a port by evaluating the benefits provided by microgrids. Zhao et al. (2020) conducted a case study of Huanghua Port, one of the largest coal transportation ports in China, to demonstrate the use of smart technologies for enhancing port sustainability. They 
found those technologies to comprise IoT, big data, automated systems, and green technology that reduces port pollution while increasing the recycling opportunity of port resources. They also stressed the importance of cooperation among port operators to smart port development.

As this literature review revealed, none of the prior research on smart ports has an advanced architecture for smart port development but focused on the unique challenges and opportunities of a smart port. Considering such shortcomings of the existing smart port literature, this paper aims to answer the following key research questions.

(1) What are the essential elements (components) that comprise a smart port architecture?

(2) How do those elements interact with each other and how can they be synchronized and integrated to make a smart port function properly?

(3) What are the roles of those elements in smart port operations?

(4) What are the value propositions and potential benefits/challenges of a smart port?

(5) How do we assess the performance of a smart port? What are the meaningful performance metrics that can gauge the smart port performance?

To answer the above questions, this paper employs a qualitative research method mainly based on content analysis. This methodology is inductive rather than deductive and provides in-depth information about the emerging smart port concepts and their managerial ramifications (Barnett-Page and Thomas 2009; Basias and Pollalis 2018; Myers 2019). The main goal of this qualitative content analysis is the systematic (iterative), concept-driven examination of recorded communication materials including the published texts and social media materials (Flick et al. 2004).

\section{A basic architecture of the smart port}

As discussed in the previous section, a smart port concept was built on the CPS, consisting of three highly integrated components: (1) computation, (2) communication, and (3) control technologies. These technologies monitor physical entities through interactions within a multi-dimensional architecture (Xu and Zhang 2014). Especially, a key role of computation (computing) technology is to extract, process, store, and analyze data. The main roles of communication technology are to transfer a large amount of data in real-time by connecting many different devices with the highest standards of data security (Dreher 2015). Control technology aims to remotely monitor asset utilization and perform corrective controls on equipment in the vessels and at the port. This control technology is linked to networked robotics, automated guided vehicles (AGVs), remotely controlled aquadrones, sensors, and actuators. Riding on the recent advancement of nanotechnology, the continuous miniaturization of sensors and actuators makes them an important part of IoT and then paves the way for smart port development by interconnecting everything online and controlling port operations without direct human involvement. In smart 
port environments, cyber and physical components are constantly coordinated, monitored, controlled, linked, and integrated by embedded computers and networked software applications via both wired and wireless links. These software applications include Enterprise Resource Planning (ERP), Terminal Operating System (TOS), Supervisory Control and Data Acquisition (SCADA), and A Programmable Logic Controller (PLC) as graphically displayed in Fig. 2.

To elaborate, ERP integrates and synchronizes all facets (multiple functional units including marketing, human resource management, logistics) of the business enterprise under one suite of software applications (Ragowsky and Summers 2002; Leon 2014). The essence of ERP systems is its ability to integrate the various functional units of an organization (including a port) using a systems/process view of the organization. Though rarely utilized in maritime logistics operations, ERP can create integrated and harmonious port planning that results in port-wide optimization with the capability to assess its overall impact on port performance (Wenrich and Ahmad 2009).

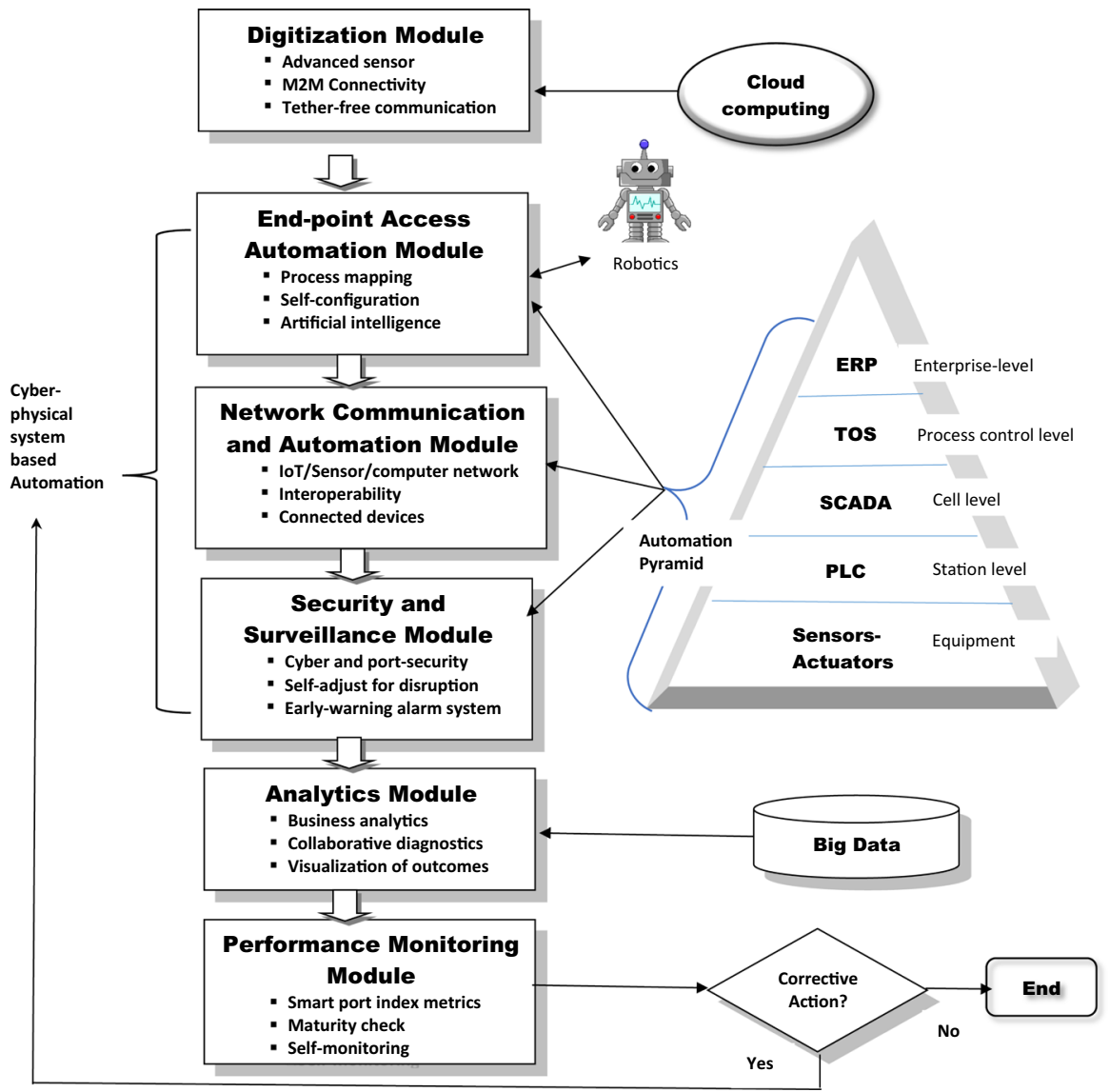

Fig. 2 A basic architecture of the prototype smart port. Source: author

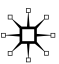


In a nutshell, TOS is designed to improve terminal operating efficiencies by efficiently allocating terminal equipment, reducing duplicated investment in the terminal equipment, providing clear instructions to terminal operators, standardizing terminal services (e.g., loading, unloading, and cargo transfers), and adapting to sudden changes in port environments through an on-line, integrated computer system (Min et al. 2017). It aims to track, trigger, guide, verify, monitor, and document every terminal activity on a real-time basis (Min et al. 2019). It also helps reduce the number of empty runs, increased terminal throughput, and turnover volume (Bartosiewicz 2014). Figure 3 illustrates TOS functionalities in greater detail. TOS can be linked and integrated with both ERP and Electronic Data Interchange (EDI).

SCADA is a system of software and hardware elements that are generally used to control dispersed assets and industrial processes locally, or at remote locations, using centralized data acquisition and supervisory control (Stouffer and Falco 2006; Boyer 2009; Inductive Automation 2018). It intends to monitor, gather, and process real-time data, while directly interacting with devices such as sensors through human-machine interface software. In addition, it records events into a log file to keep track of each action, to improve the safety and efficiency of port operations by ensuring that everything goes smoothly, and none of the equipment work outside the specified limits (Stouffer and Falco 2006; Sridhar and Manimaran 2010; Inductive Automation 2018).

In terms of industrial applications, SCADA can be used for multiple ports that are spread over much wider geographic locations, since SCADA is expected to perform

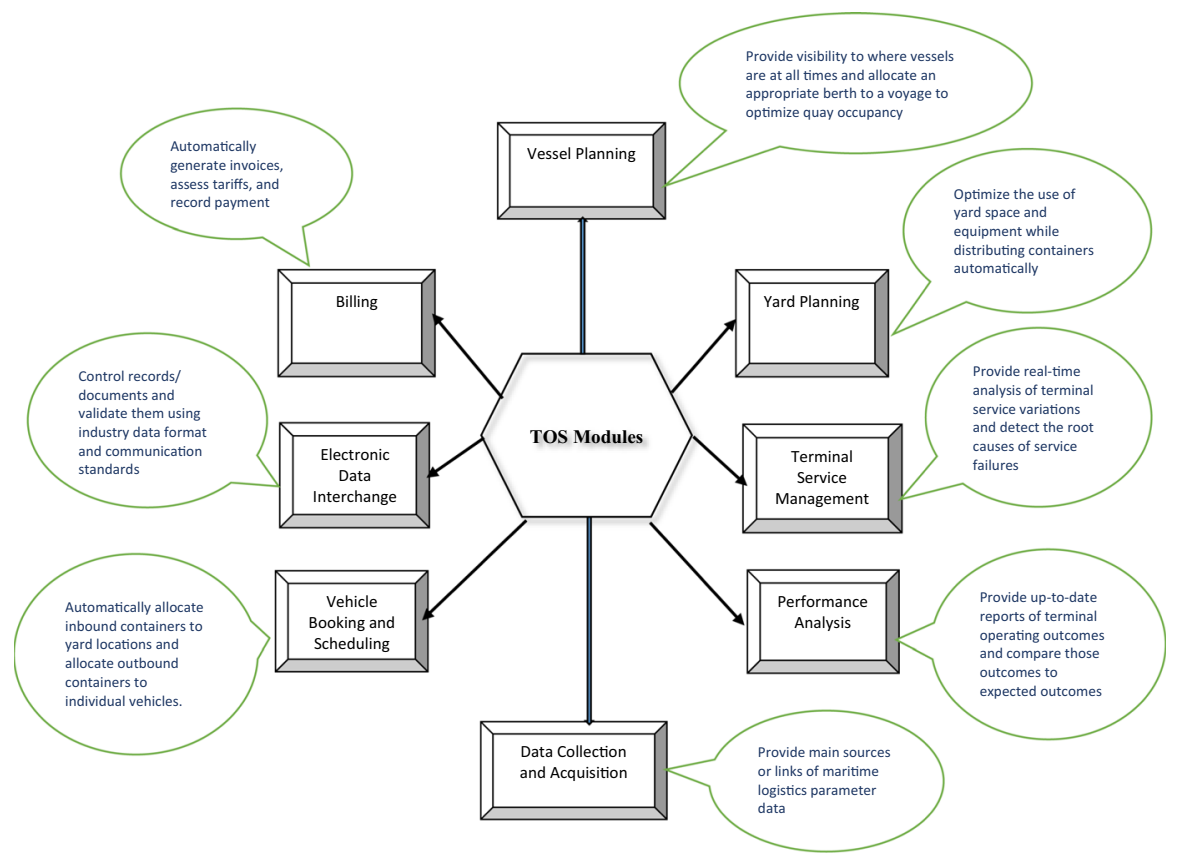

Fig. 3 Functional areas of TOS. Source: author 
when field communications fail for an extended period (Joan 2010). For example, SCADA can be used for the remote monitoring and control of terminal equipment and vehicles, the detection of port equipment failure, and the reduction of equipment failure due to its ability to alert early warning signals whenever equipment and processes do not meet measured conditions (OleumTech 2019). In a SCADA system, a Programming Logic Controller (PLC) is often used as a field device that plays the role of a remote terminal unit (RTU) and can control a specific maritime logistics process, or equipment function, when wire-based communications are unavailable. As such, PLC can help SCADA control port operations, such as collecting data from sensor systems and monitoring port activities for alarm conditions. (Stouffer and Falco 2006). SCADA and PLC can communicate with each other via shared memory. Through such communication, PLC can feed (big) data to the SCADA system. Put simply, PLC is a microprocessor-based, solid-state device that performs discrete or sequential logic to create a computer network in remotely located ports (Groover 2007). PLC generally functions by receiving information from sensors or input devices, processing the data received, and generating outputs based on guidelines pre-programmed into the device as shown in Fig. 4. These sensors can monitor key

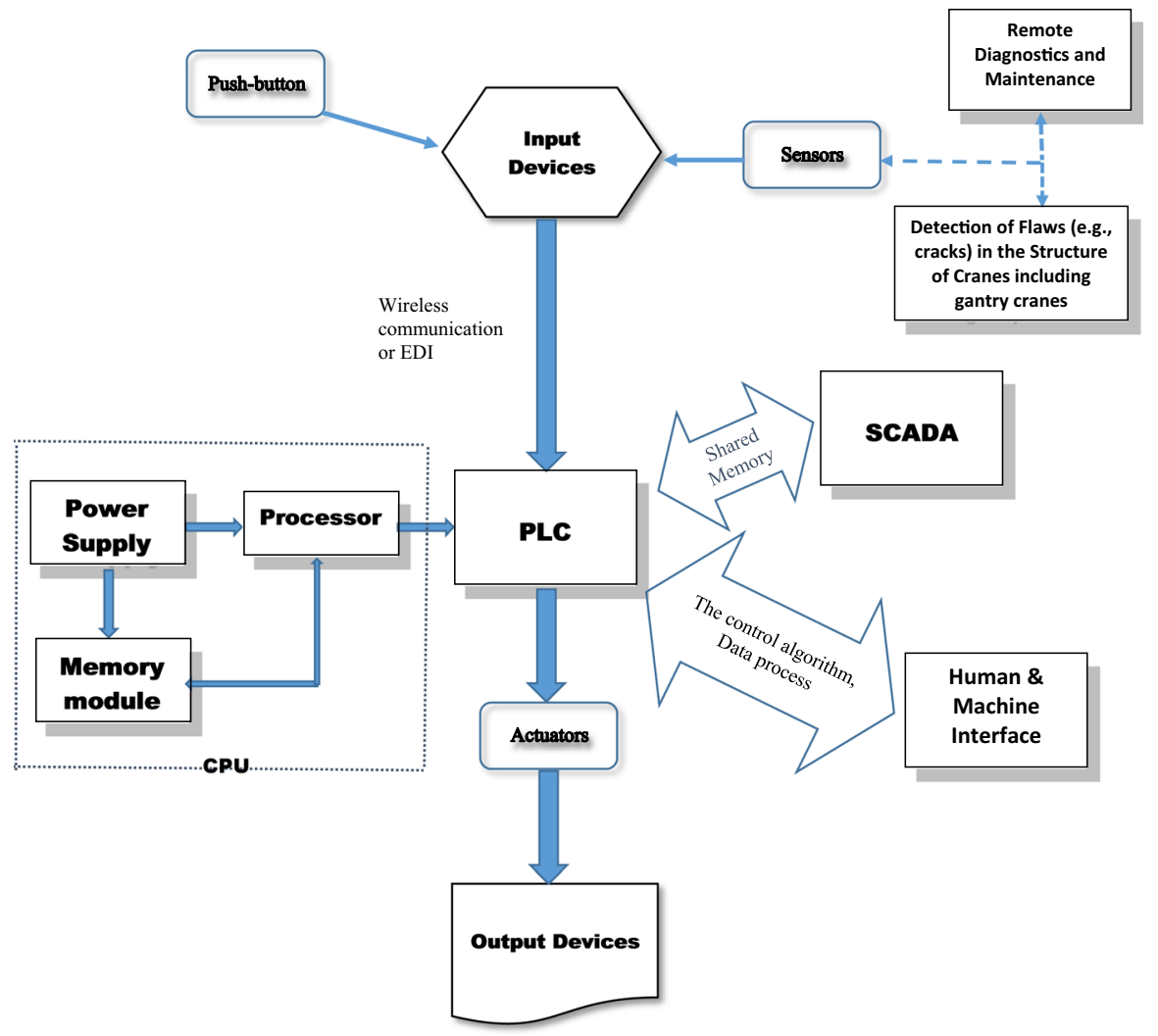

Fig. 4 PLC's architecture within the SCADA system. Source: author

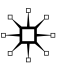


equipment operating parameters such as temperature, liquid level, force, pressure, vacuum, flow, inclination, acceleration, and vibration (Hackworth and Hackworth 2004). Every PLC consists of three main parts: Input, CPU, and Output. Depending on the inputs and outputs, a PLC can start and stop processes automatically, receive input information from remote locations and send output commands to remote locations, and generate alarms if equipment or vessel malfunctions (Swales et al. 2000; Groover 2007; FactoryMation 2018). In a nutshell, PLC can sense that equipment or vessel is not operating at the desired or optimum conditions and can automatically make adjustments to the equipment's operating parameters so that the desired performance can be sustained even when the surrounding conditions are less than ideal (Hackworth and Hackworth 2004).

\section{Managerial implications of the smart port}

Figure 5 summarizes key value drivers for smart port operations. These include (1) IoT with internal sensors that help collect real-time data within the port and subsequently support the live monitoring of port calls, yard management, vehicle planning, and customs process management; (2) CPS driven integration of IoT with physical objects that enhance M2M connectivity and thus speed up responses to shipment errors, equipment maintenance/repair needs, and safety alerts; (3) Edge computing that brings data processing power at the edge of the computer network (i.e., closer to the source of data) and thus data storage and computation can be performed locally even at the remote location. That is to say, edge computing will prevent data loss in the event of limited Internet connectivity at the remote location, and reduce decision-making time without much interruption (Mehtre 2017); (4) Mass "servitization" (delivery of service components as an added value, when making shipping arrangements) that helps develop customized self-booking and delivery schedules, utilizing business intelligence tools such as artificial intelligence (AI); (5) Intelligent automation that can emulate or imitate human actions for handling port operations, and is capable of diagnosing shipping anomalies and detecting inefficiencies on a real-time basis. Such capability prompts immediate corrective actions that suggest the right procedures or tools that help fix the problems immediately. To fully leverage these drivers, smart port operations necessitate big data that are essential for creating business intelligence and allowing smart port stakeholders to make more informed decisions. The latter should first determine what data is most important for their operations and then determine what data should be the highest priority to collect, share, analyze, and base their decisions on. In addition, the smart port authority should nurture a new age of workforce with enhanced skill sets who can adapt to more automated port environments.

A smart port setting that aims to exploit intelligent systems with machine-learning capabilities can have profound impacts on port performance. Some of those positive impacts include:

- Enhanced visibility of port activities and the subsequent supply chain operations through the integration of ERP with terminal equipment that increases 


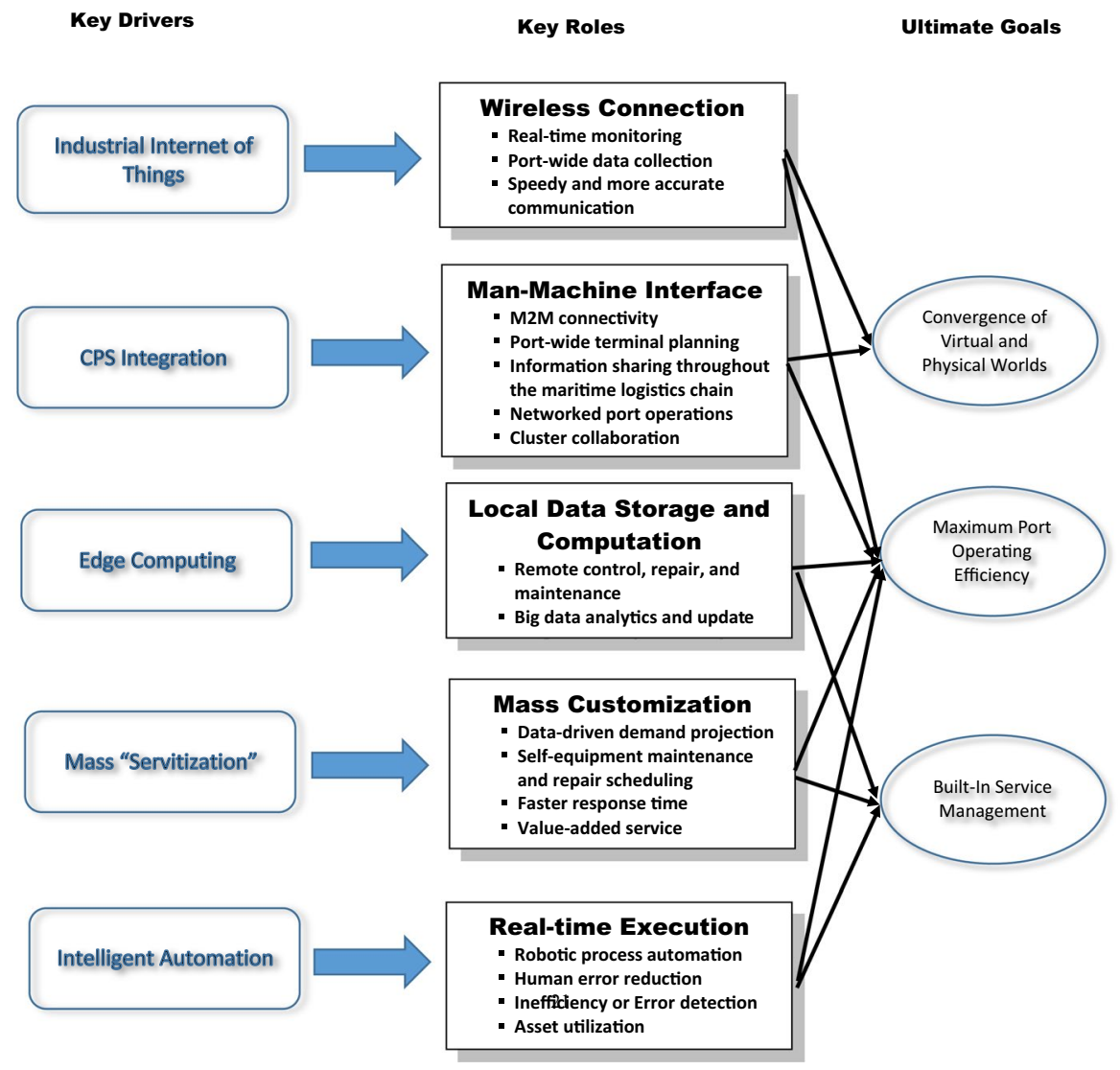

Fig. 5 Key drivers of smart port development. Source: author

real-time information availability and accessibility. Such visibility allows the port authority to see all the potential bottlenecks well in advance and take corrective actions immediately.

- Improvement in return on assets (ROAs) through better servicing of vessels, and utilization of port workers and terminal equipment.

- Reduction in human error and manpower requirements through increased automation and human-robotics cooperation without direct human involvement in the entire port operations (Luxembourg Publications Office of the European Union 2010).

- Reduced service failures or interruptions through early warning alerts of anomalies and performance monitoring with embedded sensors. For example, vibration sensing can give an early warning when cranes, AGVs, or terminal equipment need immediate upkeep and repairs (Steinmetz 2014). 
- Faster speed to market with short customer response (or lead) time and improved agility created by the embedded sensor technology that can quickly recognize demand fluctuations (Infinite Uptime 2018).

Despite the numerous merits of a smart port specified above, the concept poses many daunting challenges. These include the downgraded port work for the port workers, due to automation. This tends to transfer the skills required to perform work from human operators to automated equipment/vehicles, thus reducing the need for skilled labor and then subjugates human workers by a machine (Bright 1958). Another concern with the smart port concept is the affordability of smart port infrastructure which requires a huge start-up investment for automation, sensor technology, information technology infrastructure, and creation of business intelligence. Given that an IoT platform is essential for a smart port, other added concerns in smart port development include potential security issues (e.g., cyber-attacks) with the IoT platform. Furthermore, a smart port can pose difficulties in integrating multiple technologies that are needed for the creation, transmission, storage, and securing of data. These technologies include operational technology (OT) that detects any changes in aberrations in port activities by monitoring and controlling maritime logistics processes, physical devices, and equipment at the port.

\section{Smart port performance evaluation}

Though a smart port can bring many benefits, its full potential cannot be realized instantly. It is therefore important to monitor the progress of smart port development gradually, based on performance milestones. Monitoring and displaying smart port performance in real-time should be an essential component of a continuous improvement process. To monitor the performance of a smart port over time, a performance measurement system (PMS) should be in place. Such a PMS could comprise five steps: (1) Development of measuring attributes (e.g., performance metrics and key performance indicators (KPIs) including the smart port index); (2) Establishment of performance goals (e.g., target utilization rate per equipment and yard space, turnaround time, port traffic congestion level); (3) Setting performance criteria (e.g., berth productivity, port worker productivity, level of intermodality, energy consumption at the port, number of port calls, and liner shipping connectivity index) or benchmarks for performance comparisons; (4) Performance data collection and the detection of performance gaps or variations; (5) Taking corrective actions for performance improvement.

At the last stage of a smart port roadmap, its maturity can be subdivided into five different capability levels as summarized in Table 1 . Table 1 also proposes the potential measuring attributes that can be used to gauge the maturity level of a current smart port setting. These attributes can be a good diagnostic tool for monitoring the progress of the smart port development. In a broad sense, this maturity level can be measured in terms of both the breadth and depth of Industry 4.0 enabling technologies used by the smart port. However, given the potential impact of a smart port on innovative maritime logistics practices, the maturity level should reflect the 


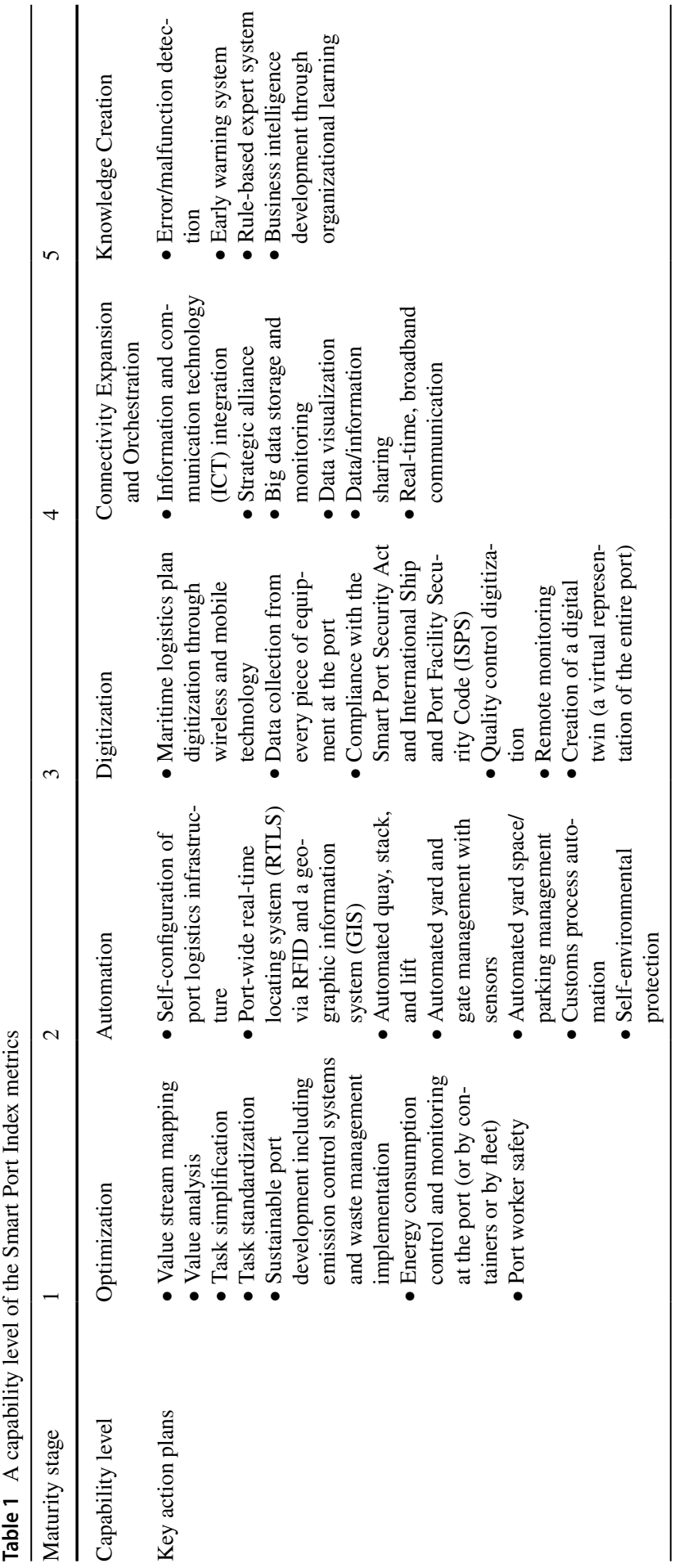

称。 


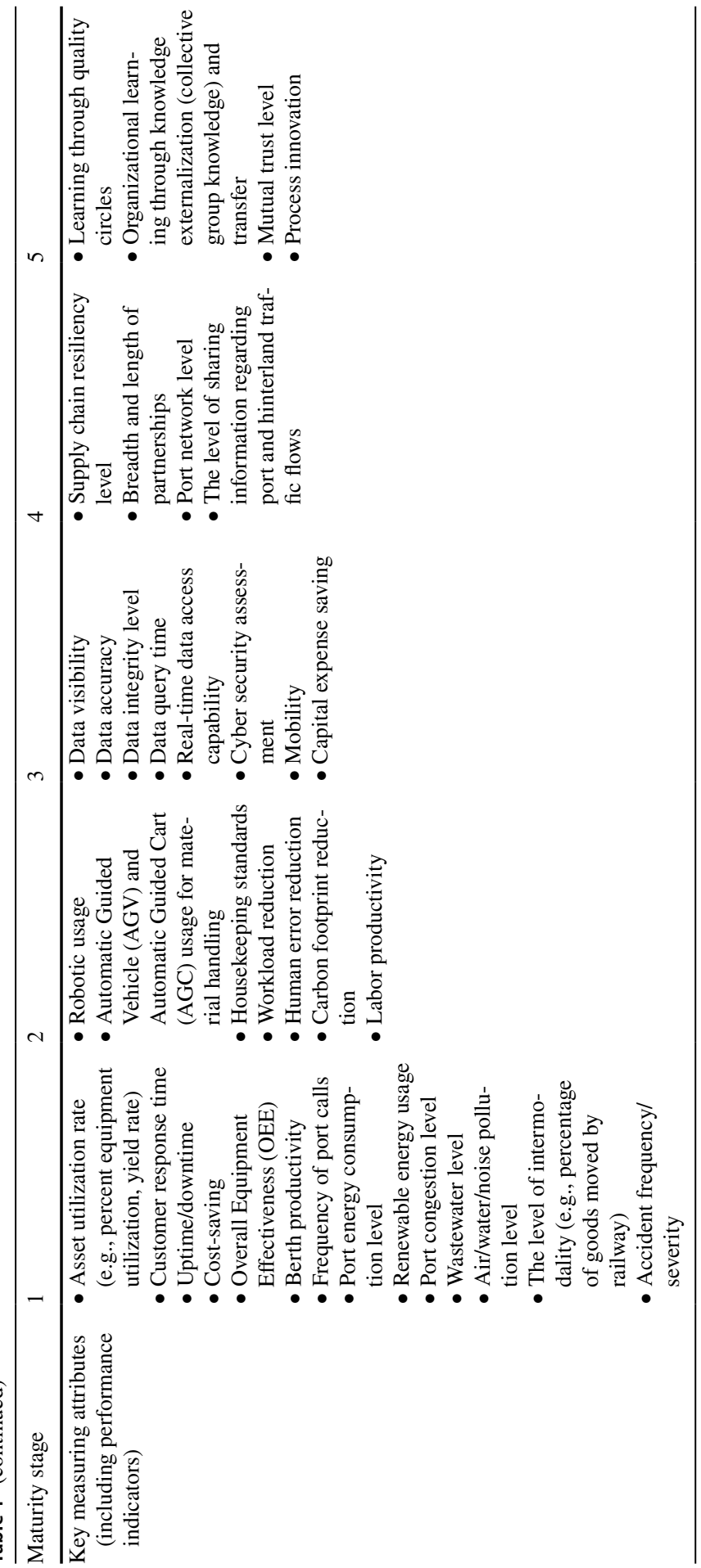


end-to-end maritime logistics transformation (including end-to-end process workflows) in addition to the extent of the use of Industry 4.0 enabling technologies. With this in mind, we divided the maturity level into five evolving stages: (1) optimization; (2) automation; (3) digitization; (4) connectivity expansion and orchestration; (5) knowledge creation. The first step of a smart port begins with the elimination of waste (or sources of inefficiency) that fits into key typologies of Industry 4.0 such as reduced equipment downtime and idle time, higher port service quality, and fast customer responses (Wan et al. 2015; Maksimchuk, and Pershina 2017). Once system optimization is accomplished, such optimization setting needs to be reiterated and routinized. Thus, automation should follow optimization. Since automation can be facilitated by Industry 4.0 enabling technologies such as intelligent robots, artificial intelligence (AI), blockchain technology, and automated guided technologies, their utilization level may reflect the degree of automation. Measuring attributes relevant to this stage are intended to gauge the extent of the use of such technologies.

Since the key element of Industry 4.0 includes the Internet of Things (IoT) platform that enables remote monitoring of port operations, the conversion of raw data available from physical information sources, such as paper documents, microfilm images, photographs, signals, and sounds into computer-readable forms is a precursor for machine-to-machine communication. Thus, at this stage, appropriate measuring attributes should represent performance metrics ensuring digital data integrity, security, accessibility, velocity, and veracity. Once digitization (transformation from physical to digital) is fully in place, M2M (machine-to-machine) connectivity will make remotely controlled smart port operations feasible and make supply chain links smooth. In particular, since secure M2M connectivity reduces the risk of supply chain disruptions under a smart port setting, measuring attributes at this stage should be designed to evaluate the strength of supply chain information/communication networks and resilience from security breaches or unforeseen supply chain risks. The ultimate goal of a smart port is to make the port truly intelligent and enhance its self-learning capabilities. That is to say, the smart port should go beyond the use of IoT devices and enabling technologies alone. Thus, it should create its capabilities to detect potential equipment/service failures, take corrective actions, and improve end-to-end maritime logistics processes. Since the creation of such capabilities starts with the creation of knowledge bases, measuring attributes relevant to this final stage should reflect the preconditions and extent of knowledge creation as illustrated by Table 1 .

\section{Conclusions and future of smart ports}

Conventional port operations in the analog age were characterized by a paper-based, reactive manual system with functional silos, which discouraged feedback, collaboration, and automation. Such operations are more vulnerable to human error and a lack of synergies among different functional units. With the advent of digital technology and a wave of Industry 4.0, a growing number of ports have begun to explore smart port planning as a more viable and sensible alternative to conventional port planning. Smart port planning helps compress customer response time, 
utilizes better assets and labor, and enhances port operating efficiency by enabling free information exchanges among port operators, shippers, and ocean carriers. Despite unprecedented benefit potentials, smart port planning poses many managerial challenges due to its newness, cyber security, and requirements for a dramatic transformation of port operation protocols. These protocols include remote monitoring and control of the port and maritime logistics activities, predictive terminal equipment maintenance, port-wide human-robot collaboration, autonomous vehicle traffic guidance, virtually guided self-service, automatic feedback generation, and automatic recovery from error. To deal with those challenges and provide practical guidance to modern ports for their smooth transition from conventional to smart port planning, this paper develops the detailed architecture of a smart port for the first time and then describes the essential components of a smart port. In addition, this paper proposes key performance indicators of smart port operations, which can help monitor the progress of smart port transformations.

To summarize, the main contribution of this paper is the creation of new knowledge bases that include the establishment of foundational conceptual frameworks and underlying protocols that enable modern ports to advance their smart port journey with a step-by-step process. These frameworks will help ports increase hidden cost-saving or revenue generation opportunities in times of austerity and unchartered new normal created by the COVID-19 pandemic. Despite our novel research attempts, this paper can be a point of departure for other follow-up studies on smart port planning. Potential future research agenda may include the examination of key drivers for smart port implementation and the assessment of the true impact of port automation on port productivity or performance.

\section{References}

Barnett-Page, E., and J. Thomas. 2009. Methods for the synthesis of qualitative research: a critical review. BMC Medical Research Methodology 9 (1): 1-11.

Bartosiewicz, A. 2014. Terminal operating systems as a tool to support entrepreneurship and competitiveness of seaports. Przedsiębiorczość i Zarzqdzanie 15: 175-187.

Basias, N., and Y. Pollalis. 2018. Quantitative and qualitative research in business \& technology: justifying a suitable research methodology. Review of Integrative Business and Economics Research 7: 91-105.

Bessid, S., A. Zouari, A. Frikha, and A. Benabdelhafid, A. 2020. Smart ports design features analysis: a systematic literature review. In Proceedings of Conference Internationale De Modelisation et Simulation (MOSIM), held on November 12-14, Agadir, Morocco, pp. 1-10.

Boyer, S.A. 2009. SCADA: Supervisory control and data acquisition. USA: International Society of Automation.

Bright, J.R. 1958. Automation and management. Boston, MA: Division of Research, Graduate School of Business Administration, Harvard University,.

Caro, F., and R. Sadr. 2019. The Internet of Things (IoT) in retail: bridging supply and demand. Business Horizons 62 (1): 47-54.

Chen, H. 2017. Applications of the cyber-physical system: a literature review. Journal of Industrial Integration and Management 2 (3): 1-28.

Chen, J., T. Huang, X. Xie, P.T.W. Lee, and C. Hua. 2019. Constructing governance framework of a green and smart port. Journal of Marine Science and Engineering 7 (4): 83-100.

Crittenden, A.B., V.L. Crittenden, and W.F. Crittenden. 2019. The digitalization triumvirate: how incumbents survive. Business Horizons 62 (2): 259-266. 
DA-14 Corp. 2018. 10 best IoT platforms in 2018: IoT technology forecast (updated). https://da-14.com/ blog/10-best-iot-platforms-iot-technology-forecast. Accessed 15 Feb 2021.

Dreher, A. 2015. Communication Technologies for the Smart Factory of the Future. St. Louis, MO: White Paper, Belden, Inc.

FactoryMation. 2018. Programmable controllers - PLC \& smart relay, https://www.factorymation.com/ Programmable_Controllers_qs. Accessed 15 Feb 2021.

Faulds, D.J., and P.S. Raju. 2019. An interview with Chuck Martin on the Internet of Things. Business Horizons 62 (1): 27-33.

Flick, U., E. von Cardorff, and I. Steinke. 2004. A companion to qualitative research. Thousand Oaks, CA: Sage Publications.

González, R.A., N. González-Cancelas, M.B. Serrano, and A.C. Orive. 2020. Preparation of a smart port indicator and calculation of a ranking for the Spanish port system. Logistics 4 (2): 9-31.

Grandview Research. 2020. Smart port market size worth $\$ 13.98$ billion by 2027. https://www.grand viewresearch.com/industry-analysis/smart-port-market?utm_source=prnewswire\&utm_medium= referral\&utm_campaign=ict_16-sept-20\&utm_term=smart-port-market\&utm_content=rd1. Accessed 5 Jan 2021.

Groover, M.P. 2007. Automation, production systems, and computer-integrated manufacturing, 3rd ed. Upper Saddle River, NJ: Prentice-Hall Press.

Hackworth, J.R., and F.D. Hackworth. 2004. Programmable logic controllers: programming methods and applications. Saddle River, NJ: Pearson Education.

Heilig, L., E. Lalla-Ruiz, and S. Voß. 2017a. Digital transformation in maritime ports: analysis and a game theoretic framework. Netnomics: Economic Research and Electronic Networking 18 (2): 227-254.

Heilig, L., S. Schwarze, and S. Voß. 2017b. An analysis of digital transformation in the history and future of modern ports. In Proceedings of the 50th Hawaii international conference on system sciences, $1341-1350$.

Inductive Automation. 2018. What is SCADA? https://inductiveautomation.com/resources/article/whatis-scada. Accessed 5 July 2021.

Joan, B. 2010. Difference between DCS and SCADA. http://www.differencebetween.net/technology/diffe rence-between-dcs-and-scada/. Accessed 5 July 2021.

Jun, W.K., M.K. Lee, and J.Y. Choi. 2018. Impact of the smart port industry on the Korean national economy using input-output analysis. Transportation Research Part a: Policy and Practice 118: 480-493.

KaaIoT Technologies. 2019. What is an IoT platform? https://www.kaaproject.org/what-is-iot-platform. Accessed 7 July 2020.

Kahn, M. 2019. What's an IoT platform and what role does it play? https://www.business.att.com/learn/ research-reports/whats-an-iot-platform-and-what-role-does-it-play.html. Accessed 7 July 2020.

Karaś, A. 2020. Smart port as a key to the future development of modern ports. TransNav: International Journal on Marine Navigation and Safety of Sea Transportation 14 (1): 27-31.

Kersey, A.D. 1996. A review of recent developments in fiber optic sensor technology. Optical Fiber Technology 2 (3): 291-317.

Lee, J. 2018. How to choose the right IoT platform: the ultimate checklist. https://hackernoon.com/howto-choose-the-right-iot-platform-the-ultimate-checklist-47b5575d4e20. Accessed 27 July 2020.

Leon, A. 2014. Enterprise resource planning. New York: McGraw-Hill Education.

Luxembourg Publications Office of the European Union. 2010. Factories of the future PPP strategic multi-annual roadmap. Unpublished report. Brussel, Belgium: EU Directorate-General for Research, Industrial Technologies.

Maglić, L., A. Grbčić, L. Maglić, and A. Gundić. 2021. Application of smart technologies in Croatian Marinas. Transactions on Maritime Science 10 (1): 178-188.

Maksimchuk, O. and T. Pershina. 2017. A new paradigm of industrial system optimization based on the conception "Industry 4.0". In Proceedings of MATEC web of conferences, vol. 129, 04006. EDP Sciences.

Min, H., S.B. Ahn, H.S. Lee, and H. Park. 2017. An integrated terminal operating system for enhancing the efficiency of seaport terminal operators. Maritime Economics \&amp; Logistics 19 (3): 428-450.

Min, H., Y.K. Lim, and J.W. Park. 2019. An integrated terminal operating system for enhancing the port security. International Journal of Logistics Systems and Management 34 (2): 193-210.

Molavi, A., G.J. Lim, and B. Race. 2020a. A framework for building a smart port and smart port index. International Journal of Sustainable Transportation 14 (9): 686-700. 
Molavi, A., J. Shi, Y. Wu, and G.J. Lim. 2020b. Enabling smart ports through the integration of microgrids: a two-stage stochastic programming approach. Applied Energy 258: 1-12.

Myers, M.D. 2019. Qualitative research in business and management. Thousand Oaks, CA: Sage Publications Limited.

NSF. 2018. Cyber-physical systems: enabling a smart and connected world. https://www.nsf.gov/news/ special_reports/cyber-physical/. Accessed 5 Jan 2021.

OleumTech. 2019. What is SCADA?. https://oleumtech.com/what-is-scada. Accessed 7 Jan 2021.

Oztemel, E., and S. Gursev. 2020. Literature review of Industry 4.0 and related technologies. Journal of Intelligent Manufacturing 31 (1): 127-182.

Ragowsky, A., and T.M. Summers. 2002. Special issue: enterprise resource planning. Journal of Management Information Systems 19 (1): 11-15.

SAS. 2018. A non-Geek's A-to-Z guide to the Internet of Things, unpublished white paper. Cary, North Carolina: SAS Institute.

Sisinni, E., A. Saifullah, S. Han, U. Jennehag, and M. Gidlund. 2018. Industrial Internet of Things: challenges, opportunities, and directions. IEEE Transactions on Industrial Informatics 14 (1): 4724-4734.

Ślusarczyk, B. 2018. Industry 40-Are we ready. Polish Journal of Management Studies 17 (1): 232-248.

Sridhar, S. and G. Manimaran. 2010. Data integrity attacks and their impacts on SCADA control system. In Power and energy society general meeting, 2010 IEEE, 1-6. IEEE.

Steinmetz, K. 2014. Advancing the smart factory through technology innovation. Texas Instruments: Unpublished Report, Dallas, Texas.

Stouffer, K. and J. Falco. 2006. Guide to supervisory control and data acquisition (SCADA) and industrial control systems security, Special Publication 800-82, National Institute of Standards and Technology. Washington DC: U.S. Department of Commerce.

Swales, A.G., R. Naismith, R. Breinlinger, R.A. Baker Jr, A.D. Papadopoulos, A., Tanzman, R.G. Belliardi, and D.J. Dube. 2000. Internet web interface including programmable logic controller for controlling output devices based on status of input devices. U.S. Patent 6,151,625. Schneider Automation Inc.

Wan, J., H. Cai, K. Zhou. 2015. Industry 4.0: Enabling technologies. In Proceedings of 2015 international conference on intelligent computing and Internet of Things, 135-140.

Wang, L., G. Von Laszewski, A. Younge, X. He, M. Kunze, J. Tao, and C. Fu. 2010. Cloud computing: a perspective study. New Generation Computing 28 (2): 137-146.

Wenrich, K., and N. Ahmad. 2009. Lessons learned during a decade of ERP experience: a case study. International Journal of Enterprise Information Systems 5 (1): 55-73.

Wilson, J.S. 2005. Sensor technology handbook. Amsterdam, Netherlands: Elsevier.

Xia, F., L.T. Yang, L. Wang, and A. Vinel. 2012. Internet of Things. International Journal of Communication Systems 25 (9): 1101-1102.

Xu, B., and L. Zhang. 2014. Multi-dimensional architecture modeling for cyber physical systems. In Advances in computer science and its applications, 101-105. Berlin: Springer.

Yang, Y., M. Zhong, H. Yao, F. Yu, X. Fu, and O. Postolache. 2018. Internet of Things for smart ports: Technologies and challenges. IEEE Instrumentation \&amp; Measurement Magazine 21 (1): 34-43.

Yau, K.L.A., S. Peng, J. Qadir, Y.C. Low, and M.H. Ling. 2020. Towards smart port infrastructures: enhancing port activities using information and communications technology. IEEE Access 8: 83387-83404.

Zhao, D., T. Wang, and H. Han. 2020. Approach towards sustainable and smart coal port development: the case of Huanghua port in China. Sustainability 12 (9): 3924-3947.

Publisher's Note Springer Nature remains neutral with regard to jurisdictional claims in published maps and institutional affiliations. 